\title{
HEMATOLOGIA COMPARADA ENTRE DIPLÓIDES E TRIPLÓIDES DE TRUTA ARCO-ÍRIS, ONCORHYNCHUS MYKISS WALBAUM (PISCES, SALMONIDAE)
}

\author{
Maria José Tavares Ranzani-Paiva ${ }^{1,3}$ \\ Yara Aiko Tabata ${ }^{2}$ \\ Augusta Cocuzza das Eiras ${ }^{1}$
}

\begin{abstract}
COMPARATED hEMATOLOGY BETWEEN DIPLOIDS AND TRIPLOIDS OF RaINBOW Trout, ONCORHYNCHUS MYKisS Walbaum (PISCES, Salmonidae). This study was carried out at the Salmoniculture Experimental Station "Dr. Ascanio de Faria", in Campos do Jordão, São Paulo, Brazil. The aim was to compared the hematology of triploid and diploid rainbow trout, Oncorhynchus mykiss Walbaum, 1792, by sex and gonadal maturation stages. Blood was obtained from 144 individuals for determinations of: haemoglobin rate $(\mathrm{Hb})$, haematocrit $(\mathrm{Ht})$, erythrocyte count $(\mathrm{Er})$, mean corpuscular volume (MCV), mean corpuscular haemoglobin (MHC), mean corpuscular hemoglobin concentration (MCHC), and differential leucocyte counts. The ploid was determinated by measuring the erythrocyte major axis, in fresh and stainned smears. Triploid rainbow trout had a large erythrocyte diameter, mean erythrocyte volume and mean haemoglobin concentration, but lower erythrocyte count than diploid. Lymphocytes was the most frequent cell in peripherical blood. There was no difference between males and females for all parameters here analysed. The haematological analyses showed signifficant increase with the development of gonadal maturation stages.

KEY WORDS. Oncorhynchus mykiss, diploid, triploid, hematolology, rainbow trout
\end{abstract}

A triploidização é uma técnica que vem sendo aplicada em peixes com o propósito de se induzir a esterilidade reprodutiva. Essa esterilidade é atribuída à presença do conjunto cromossômico extra, que causa a interrupção da meiose I, na gametogênese, resultando em diferentes níveis de supressão do desenvolvimento gonadal (DONALDSON \& HunTER 1982; THORGAARD 1983; PURDOM 1983; IHSSEN et al. 1990).

$\mathrm{Na}$ criação comercial de trutas, os principais benefícios decorrentes da triploidização consistem no maior crescimento corpóreo, na melhoria da qualidade da carne e na redução da mortalidade, após a idade de primeira maturação sexual (UTTER et al. 1983; BYE \& LINCOLN 1986).

$\mathrm{O}$ aumento do conteúdo de DNA resultante da triploidia leva a um aumento do volume celular e nuclear em um grande número de tecidos, mas o número de células é reduzido para manter normal o tamanho do corpo e dos órgãos (SWARUP 1959; Benfey \& SutTerlin 1984b; SMAll \& BenFey 1987).

1) Instituto de Pesca, Divisão de Pesca Interior. Avenida Francisco Matarazzo 455, 05031-900 São Paulo, São Paulo, Brasil.

E-mail: ipesca@eu.ansp.br

2) Instituto de Pesca, Estação Experimental de Salmonicultura Dr. Ascânio de Faria. Caixa Postal 361, 12470-000 Campos de Jordão, São Paulo, Brasil.

3) Bolsista do CNPq. 
Entre os estudos de hematologia de animais triplóides aparecem trabalhos com peixes (CHERFAS 1966; Cimino 1973; SEZAKI et al. 1988). Existem evidências de que os eritrócitos e seus núcleos são maiores nos peixes triplóides que nos diplóides (SWARUP 1959). Estes autores encontraram que o aumento do volume do eritrócito em triplóides é compensado pelo decréscimo no seu número, deste modo, o hematócrito e a taxa de hemoglobina contidos são os mesmos em diplóides e triplóides.

A redução do número de eritrócitos provoca um decréscimo na capacidade de transporte de oxigênio (GRAHAM et al. 1985) e quando submetidos exercício prolongado, os triplóides apresentam uma menor capacidade aeróbica do que os diplóides (VIRTANEN et al. 1990).

Sob condições de cultivo intensivo, os salmonídeos são estocados em altas densidades e ficam sujeitos, ocasionalmente, a hipóxia moderada ou severa. Esse estresse associado a enfermidades de brânquias e deficiências nutricionais, favorecem o desenvolvimento de anemia. Assim, qualquer alteração no quadro hemático, que interfira na habilidade do peixe em utilizar oxigênio, pode afetar o seu desempenho nos cultivos (BENFEY \& SUTTERLIN 1984a).

O presente trabalho teve por objetivo comparar as características hematológicas entre trutas diplóides e triplóides, em diferentes estádios do ciclo reprodutivo.

\section{MATERIAL E MÉTODOS}

Os exemplares de truta arco-íris, Oncorhynchus mykiss Walbaum, 1792, utilizados neste trabalho, foram cultivados na "Estação Experimental de Salmonicultura Dr. Ascânio de Faria", do Instituto de Pesca, localizada no município de Campos do Jordão, São Paulo. Os exemplares triplóides foram obtidos através de choque térmico em ovos recém fertilizados, segundo CHOURROUT (1980). No início do experimento os exemplares estavam com a idade de 12 meses.

Mensalmente, capturaram-se 12 exemplares diplóides e 12 triplóides, durante o período de $24 / \mathrm{IX} / 1992$ a 23/XI/1993, na proporção de $50 \%$ machos e $50 \%$ fêmeas.

Os peixes foram anestesiados com benzocaina (100 mg/litro), pesados, medidos (comprimento total) e o sangue retirado por punção caudal, com auxílio de seringas e agulhas descartáveis, heparinizadas. Os seguintes exames foram realizados: 1) taxa de hemoglobina $(\mathrm{Hb})$, pelo método da cianometahemoglobina, segundo COLLIER (1944); 2) relação glóbulo plasmática (hematócrito-Ht), através do método do microhematócrito, segundo GoLDENFARB et al. (1971); 3) número de eritrócitos (Er), realizada em câmaras de Neubauer, sendo o sangue diluído com a solução de Hayem; 4) cálculo dos índices hematimétricos: volume corpuscular médio (VCM), hemoglobina corpuscular média (HCM) e concentração de hemoglobina corpuscular média (CHCM), segundo WINTROBE (1934); 5) contagem diferencial dos leucócitos, feita em extensões coradas pelo método de ROSENFELD (1947).

Após a retirada do sangue, os peixes foram sacrificados por comoção cerebral, e submetidos a uma incisão abdominal, para determinação macroscópica 
do sexo e dos estádios de maturação gonadal, em: imaturo, maturação inicial, maturação avançada, maduro e regressão (PAIVA et al. 1985) e as fêmeas triplóides em estéreis (LINCOLN \& SCOTT 1984).

Para confirmar a triploidia, foram medidos o maior eixo dos eritrócitos nas extensões sangüíneas, de todos os exemplares segundo metodologia de BENFEY et al. (1984).

A diferença entre as médias dos diâmetros dos eritrócitos realizada em extensões sangüíneas a fresco e coradas de indivíduos diplóides e triplóides, foram testadas pelo teste $\mathbf{t}$ de Student, segundo CosTA NeTO (1977).

Foram calculadas as médias, os desvios padrão das médias e os intervalos de confiança dos parâmetros de indivíduos diplóides e triplóides, separadamente por sexo e por estádio de maturação gonadal.

Para verificar a influência dos fatores biológicos (sexo e estádio) sobre os dados hematológicos utilizou-se o programa de computação LSMLMW (HARVEY 1987), com análises feitas pelo método dos mínimos quadrados, devido ao número desigual de repetições nas subclasses dos efeitos estudados.

\section{RESULTADOS E DISCUSSÃO}

Foi analisado um total de 288 espécimens de truta arco-íris, sendo 144 diplóides ( 77 machos e 67 fêmeas) e 144 triplóides (12 indiferenciados, 72 machos e 60 fềmeas).

Os diplóides apresentaram amplitude de variação do comprimento total de 25,0 a $51,0 \mathrm{~cm}$ e do peso total de 200,0 a 2.080,0 g e os triplóides de 25,5 a 53,5 cm e de 230,0 a $2020,0 \mathrm{~g}$, respectivamente.

Na tabela I estão apresentados os valores médios dos diâmetros dos eritrócitos e os valores de $\mathbf{t}$ de Student, comparando-se as medidas dos diâmetros realizadas em extensões a fresco e coradas, de diplóides e triplóides. Nota-se que há diferença significativa $(\mathrm{p}>0,05)$ entre os dois grupos, com os triplóides apresentando valores médios dos diâmetros dos eritrócitos superiores aos dos diplóides e que a coloração, embora tenha causado certa retração das células, esta não foi significativa.

Tabela I. Médias $(\bar{x})$ e desvios padrão das médias $(S \bar{x})$ dos diâmetros dos eritrócitos de Oncorhynchus mykiss, diplóides e triplóides, em extensões a fresco e coradas.

\begin{tabular}{lccc}
\hline & \multicolumn{3}{c}{ Diâmetro dos eritrócitos } \\
\cline { 2 - 4 } & A fresco & Corado & $\mathrm{t}$ \\
\hline $\bar{x}$ & $2 \mathrm{n}$ & $\mathbf{2 n}$ & \\
$\mathrm{s} \overline{\mathrm{x}}$ & 15,32 & 14,94 & 1,12 n.s. \\
& 0,26 & 0,25 & \\
$\bar{x}$ & $3 \mathrm{n}$ & $3 \mathrm{n}$ & 0,31 n.s. \\
$\mathrm{S} \overline{\mathrm{x}}$ & 20,96 & 20,83 & \\
$\mathrm{t}$ & 0,35 & 0,23 & \\
\hline
\end{tabular}

*) Significativo a $5 \%$ de probabilidade; (n.s.) não significativo. 
As medidas dos diâmetros dos eritrócitos podem ser um instrumento válido para distinguir entre diferentes níveis de ploidia tanto em populações naturais, como em cativeiro. As extensões sangüíneas podem ser facilmente feitas em campo e coradas mais tarde, identificando-se rapidamente grande número de indivíduos (CIMINo 1973). Além disso, essas mesmas extensões poderão ser utilizadas posteriormente para a contagem diferencial dos leucócitos e a medida dos diâmetros pode ser também feita em extensões coradas, não alterando a identificação da ploidia.

PALACIOS et al. (1987) também compararam as medidas do diâmetro de eritrócitos e do núcleo em extensões sangüíneas a fresco e coradas, de alguns vertebrados, verificando que os corantes vitais parecem não afetar o tamanho da célula, não havendo diferença nas dimensões celulares, como ocorreu no presente trabalho.

As amplitudes de variação, médias e desvios padrão das médias das variáveis hematológicas para o total de indivíduos diplóides e triplóides estão representados na tabela II. Por essa tabela nota-se que a triploidia causa redução do Er e do Ht em $35 \%$ e $5 \%$, respectivamente, aumentando o volume dos eritrócitos em $33 \%$.

Tabela II. Amplitudes de variação $(A \bar{x})$, médias $(\bar{x})$ e desvios padrão das médias $(S \bar{x})$ das análises hematológicas de Oncorhynchus mykiss diplóides $(2 n)$ e triplóides $(3 n)$. (Ht) Hematócrito, (VCM) volume corpuscular médio, $(\mathrm{Hb})$ taxa de hemoglobina, $(\mathrm{HCM})$ hemoglobina corpuscular média; (Er) número de eritrócitos, ( $\mathrm{CHCM}$ ) concentração de hemoglobina corpuscular média.

\begin{tabular}{lccccccc}
\hline Ploidia & $\begin{array}{c}\mathrm{Ht} \\
(\%)\end{array}$ & $\begin{array}{c}\mathrm{Hb} \\
(\mathrm{g} / / 100 \mathrm{ml})\end{array}$ & $\begin{array}{c}\mathrm{Er} \\
\left(10^{4} / \mu \mathrm{l}\right)\end{array}$ & $\begin{array}{c}\mathrm{VCM} \\
\left(\mu^{3}\right)\end{array}$ & $\begin{array}{c}\mathrm{HCM} \\
(\mathrm{pg})\end{array}$ & $\begin{array}{c}\mathrm{CHCM} \\
(\%)\end{array}$ \\
\hline $2 \mathrm{n}$ & $\mathrm{Ax}$ & $29,50-67,00$ & $3,65-12,52$ & $60,50-248,00$ & $19,56-73,55$ & $22,26-139,50$ & $9,71-30,84$ \\
$\mathrm{n}=144$ & $\bar{x}-\bar{x}$ & 44,88 & 8,75 & 144,80 & 31,83 & 62,13 & 19,56 \\
& $\mathrm{~S} x$ & 0,29 & 0,07 & 1,25 & 0,27 & 0,59 & 0,13 \\
$3 \mathrm{n}$ & $\mathrm{Ax}$ & $27,50-64,00$ & $3,30-15,15$ & $23,00-160,00$ & $28,96-143,48$ & $31,43-291,30$ & $8,25-37,41$ \\
$\mathrm{n}=144$ & $\bar{x}$ & 42,85 & 8,36 & 94,58 & 47,36 & 92,67 & 19,61 \\
& $\mathrm{~S} \bar{x}$ & 0,35 & 0,08 & 0,96 & 0,56 & 1,26 & 0,16 \\
\hline
\end{tabular}

*) Significativo a $5 \%$ de probabilidade; (n.s.) não significativo.

Pela análise do método dos mínimos quadrados apresentada na tabela III, encontrou-se que as diferenças entre as médias de Er, VCM e HCM são significativamente diferentes entre diplóides e triplóides. Não foram encontradas diferenças significativas entre machos e fêmeas. Desta maneira, nas figuras 1 e 2, onde são consideradas as médias das análises sangüíneas e dos índices hematimétricos absolutos dos indivíduos diplóides e triplóides, analisados por estádios de maturação gonadal, pode-se notar que esses valores aumentaram com o avanço da maturação gonadal, para os indivíduos diplóides e que estas diferenças são significativas, conforme dados da tabela III.

Os valores médios dos parâmetros hematológicos dos indivíduos diplóides são compatíveis com os da literatura (MCCARTHY et al. 1973; MEADE \& PERRONE 1980).

A incorporação de um conjunto cromossômico haplóide geralmente causa aumento do tamanho das células, sendo o núcleo dos eritrócitos dos triplóides maior que o dos diplóides, porém a relação núcleo-citoplasma permanece a mesma 
(SWARUP 1959; BECK \& BIGGERS 1983; SEZAKI et al. 1988). Entretanto, os animais triplóides não são maiores que os diplóides, devido a uma redução do número de células (BENFEY \& SUTTERLIN 1984a). Isto também, pode ser verificado em truta arco-íris, como aqui demonstrado pelo aumento significativo do diâmetro e redução do número dos eritrócitos dos indivíduos triplóides.

Tabela III. Resultados das análises estatísticas pelos métodos dos minimos quadrados, das variáveis sangüineas de Oncorhynchus mykiss, diplóides $(2 n)$ e triplóides $(3 n)$. (Ht) Hematócrito $(\%),(\mathrm{VCM})$ volume corpuscular médio $\left(\mu^{3}\right),(\mathrm{Hb})$ taxa de hemoglobina $(\mathrm{g} / 100 \mathrm{ml}),(\mathrm{HCM})$ hemoglobina corpuscular média $(\mathrm{pg}),(\mathrm{Er})$ número de eritrócitos $\left(10^{4} / \mu \mathrm{l}\right),(\mathrm{CHCM})$ concentraçăo de hemoglobina (\%).

\begin{tabular}{lcccccc}
\hline & $\begin{array}{c}\mathrm{Ht} \\
(\%)\end{array}$ & $\begin{array}{c}\mathrm{Hb} \\
(\mathrm{g} / / 100 \mathrm{ml})\end{array}$ & $\begin{array}{c}\mathrm{Er} \\
\left(10^{4} / \mu \mathrm{l}\right)\end{array}$ & $\begin{array}{c}\mathrm{VCM} \\
\left(\mu^{3}\right)\end{array}$ & $\begin{array}{c}\mathrm{HCM} \\
(\mathrm{pg})\end{array}$ & $\begin{array}{c}\mathrm{CHCM} \\
(\%)\end{array}$ \\
\hline Ploidia & 1,47 & 0,01 & $98,91^{\star \star}$ & $92,09^{\star *}$ & $63,280^{* *}$ & 0,37 \\
Sexo & 0,01 & 0,95 & 0,16 & 0,32 & 0,003 & 0,95 \\
Estádio & $13,40^{\star \star}$ & $8,96^{\star *}$ & $2,89^{\star}$ & 0,77 & 0,830 & 1,62 \\
\hline
\end{tabular}

(*) Significativo a $5 \%$ de probabilidade; $\left({ }^{* *}\right)$ significativo a $1 \%$ de probabilidade.
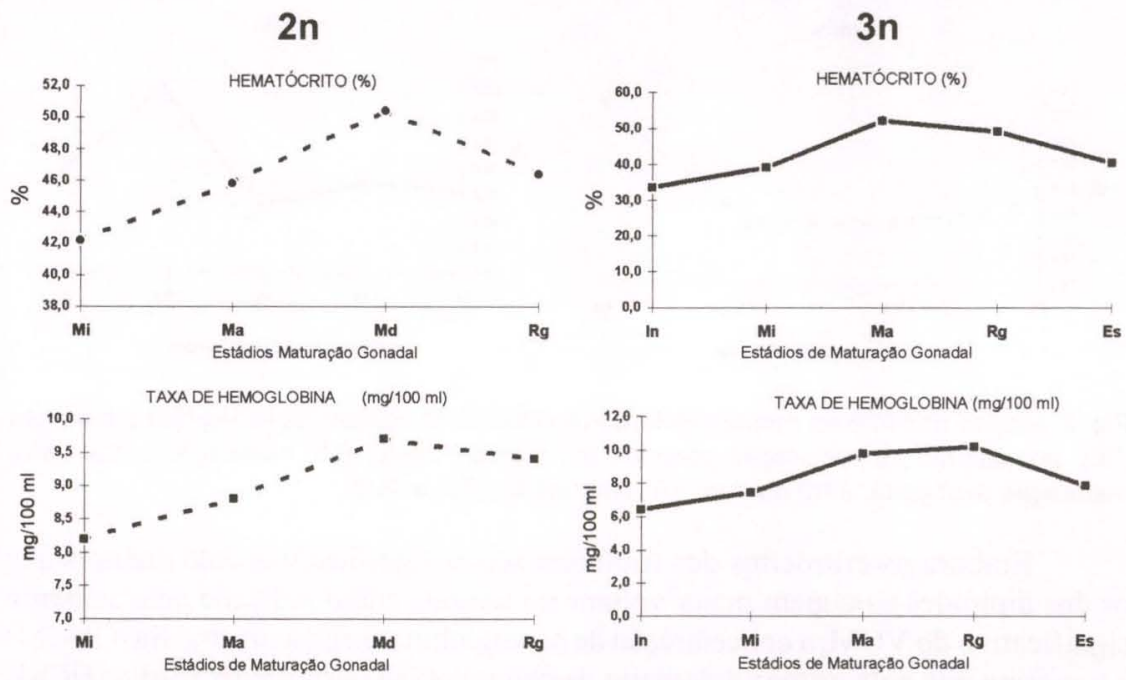

NN DE ERITRÓCITOS (10 4/ul)
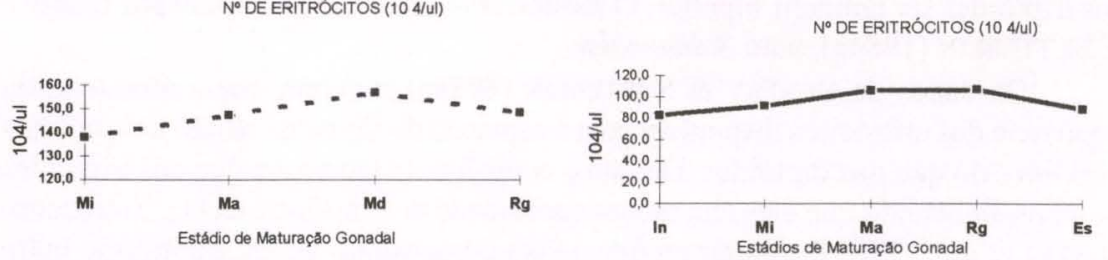

Fig. 1. Médias das análises hematológicas de truta arco-íris, O. mykiss, diplóides $(2 n)$ e triplóides (3n), por estádio de maturação gonadal. (In) Indeterminado, (Mi) maturação inicial, (Ma) maturação avançada, (Md) maduro, (Rg) regressão, (Es) estéril. 
2n
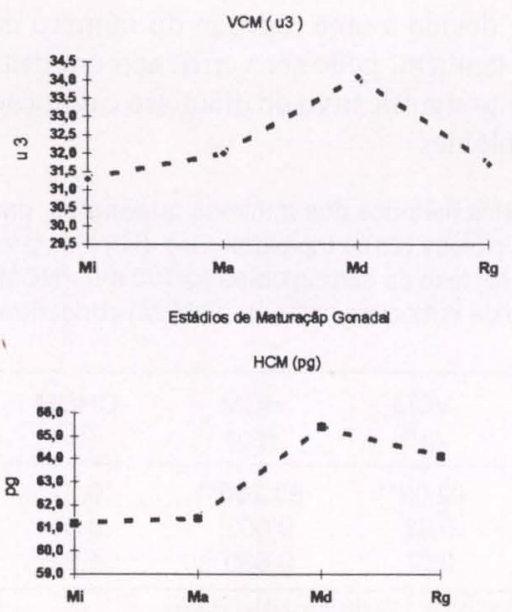

Estadios de Maturaça Gonadal

CHCM (\%)

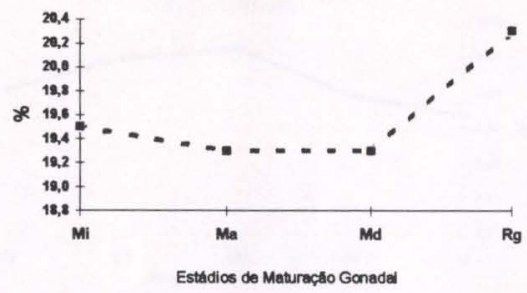

$3 n$
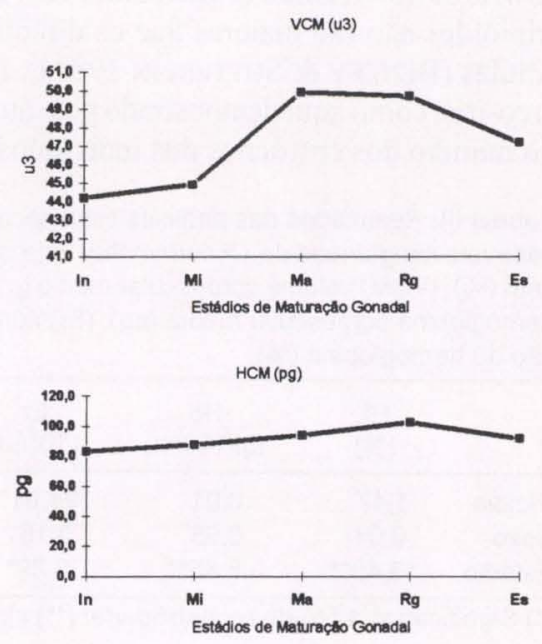

$\operatorname{CHCM}(\%)$

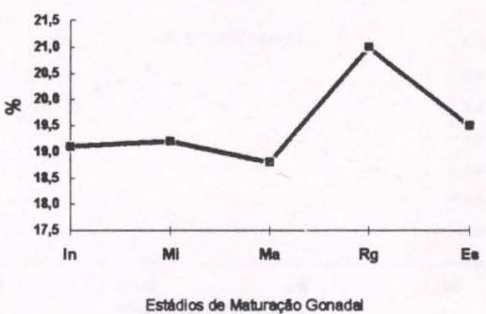

Fig. 2. Médias dos índices hematimétricos absolutos de O. mykiss, diplóides (2n) e triplóides $(3 n)$, por estádio de maturação gonadal. (In) Indeterminado, (Mi) maturação inicial, (Ma) maturação avançada, (Md) maduro, $(\mathrm{Rg})$ regressão, (Es) estéril.

Embora os eritrócitos dos triplóides sejam significativamente maiores que os dos diplóides e ocupem maior volume no sangue, como indicado pelo aumento significativo do VCM, a concentração de hemoglobina corpuscular média (CHCM) é a mesma nos dois grupos a despeito da hemoglobina corpuscular média (HCM) dos triplóides ser também superior. O mesmo resultado foi encontrado por BENFEY \& SUTTERLIN (1984a), para Salmo salar.

Os dados de BENFEY \& SUTTERLIN (1984a) sugerem que a área total da superfície dos eritrócitos disponível para a captação do $\mathrm{O}_{2}$ pelos peixes é menor nos triplóides do que nos diplóides. De fato o conteúdo de $\mathrm{Hb}$ no sangue dos triplóides é menor, indicando que eles têm menor capacidade de transporte de $\mathrm{O}_{2}$. Entretanto, SEZAKI et al. (1988) encontraram que a taxa de consumo de $\mathrm{O}_{2}$ é a mesmo entre diplóides, triplóides e tetraplóides de Cobitis biwae. Esses autores não encontraram diferença nas concentrações de $\mathrm{Hb}$, de $\mathrm{Ht}$ ou de $\mathrm{CHCM}$, como o encontrado no presente trabalho. Embora os tetraplóides tenham eritrócitos maiores e em número 
menor, parecendo ser uma pequena desvantagem na taxa metabólica, os dados demonstram, aparentemente, um mecanismo similar de atividade enzimática de regulação de eritrócitos. Comparando tetraplóides com diplóides estes autores encontraram $\mathrm{Ht}$ e $\mathrm{Hb}$ similares, sugerindo que as suas atividades gerais ou respiratórias também podem ser comparáveis.

As trutas arco-íris apresentam ciclo reprodutivo anual, sendo os meses de maio a agosto a época da reprodução desta espécie, no Brasil. Esses meses correspondem às mais baixas temperaturas da água e do ar, na região de coleta. As diferenças significativas encontradas nas médias das variáveis hematológicas durante o ciclo reprodutivo de truta arco-íris, podem estar associadas à temperatura da água, ou ao fato de, nesta época do ciclo, os peixes deixarem de se alimentar e passarem a usar suas próprias reservas energéticas, ou à maior atividade metabólica na época da reprodução. Este é um comportamento encontrado em várias espécies de peixes de água doce ou salgada, tanto na natureza (RANZANI-PAIVA \& GODINHO 1985; RANZANI-PAIVA 1995) como em cativeiro (HARDIG \& HoGLUND 1984; PAIVA 1991).

No sangue periférico de truta arco-íris diplóides e triplóides foram encontradas as células: linfócitos, monócitos, neutrófilos e células imaturas (Tab. IV).

Tabela IV. Amplitudes de variação $(A x)$, médias $(\bar{x})$ e desvios padrão das médias $(S \bar{x})$ das contagens diferenciais dos leucócitos de Oncorhynchus mykiss diplóides (2n) e triplóides (3n).

\begin{tabular}{llcccc}
\hline & $\begin{array}{c}\text { Linfócitos } \\
(\%)\end{array}$ & $\begin{array}{c}\text { Monócitos } \\
(\%)\end{array}$ & $\begin{array}{c}\text { Neutrófilos } \\
(\%)\end{array}$ & $\begin{array}{c}\text { Imaturas } \\
(\%)\end{array}$ \\
\hline $2 \mathrm{n}$ & $\mathrm{Ax}$ & $39,80-100,00$ & $0,00-8,50$ & $0,00-57,80$ & $0,00-4,30$ \\
$\mathrm{n}=144$ & $\bar{x}$ & 87,32 & 0,81 & 11,40 & 0,47 \\
& $\mathrm{~S} \bar{x}$ & 0,91 & 0,12 & 0,85 & 0,07 \\
$3 \mathrm{n}$ & $\mathrm{Ax}$ & $41,20-100,00$ & $0,00-9,30$ & $0,00-57,80$ & $0,00-10,20$ \\
$\mathrm{n}=144$ & $\bar{x}$ & 91,42 & 0,52 & 7,73 & 0,31 \\
& $\mathrm{~S} \bar{x}$ & 0,73 & 0,11 & 0,68 & 0,08 \\
\hline
\end{tabular}

Considerando-se a contagem diferencial dos leucócitos, foram calculadas as médias das porcentagens de cada leucócito, para diplóides e triplóides, apresentadas na tabela IV. Os linfócitos foram as células mais freqüentes em ambos os grupos de peixes. Não foram encontradas diferenças entre diplóides e triplóides, pelo método dos mínimos quadrados (Tab. V).

Tabela V. Resultados das análises estatísticas pelos métodos dos mínimos quadrados, das porcentagens de leucócitos de Oncorhynchus mykiss, diplóides (2n) e triplóides (3n). (Lf) Linfócitos, (Nt) neutrófilos, (Mn) monócitos, (Imat) células imaturas.

\begin{tabular}{lcccc}
\hline Fonte & Linfócitos & Monócitos & Neutrófilos & Imaturas \\
\hline Ploidia & 0,11 & 0,04 & 0,05 & 1,17 \\
Sexo & 0,53 & 0,12 & 0,52 & 0,05 \\
Estádio & $7,56^{*}$ & $4,60^{*}$ & $7,92^{*}$ & 1,22 \\
\hline
\end{tabular}

$\left({ }^{\star}\right)$ Significativo a $1 \%$ de probabilidade. 
Por esta tabela nota-se que há diferença significativa apenas entre as médias analisadas por estádio de maturação gonadal. Na figura 3, onde estas médias são representadas, nota-se que há, também, aumento das médias com o avanço da maturação gonadal. Este achado não é semelhante ao encontrado na literatura, onde pode-se constatar que, para algumas espécies, apenas linfócitos e neutrófilos apresentam, alteração nos diferentes estádios de maturação gonadal. Por exemplo, PiCKERING (1986) constatou, para Salmo trutta, redução visível do número de linfócitos circulantes em exemplares sexualmente maduros, quando comparados com indivíduos imaturos, enquanto que a freqüência dos neutrófilos em machos maduros foi maior que nos imaturos.

2n

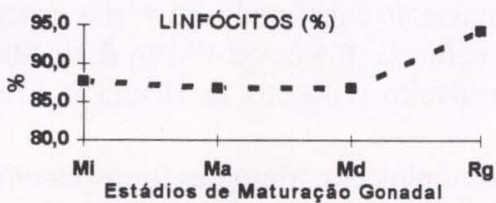

MONOCITOS (\%)

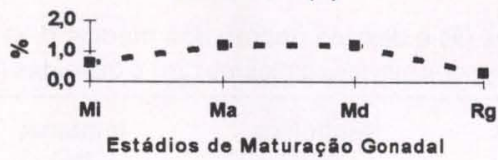

NEUTRÓFILOS (\%)

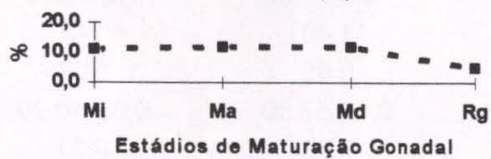

CÉL. IMATURAS (\%)

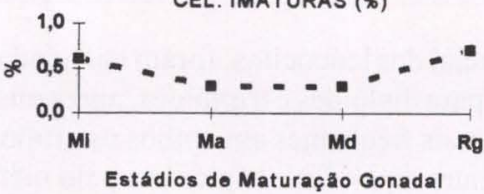

$3 n$

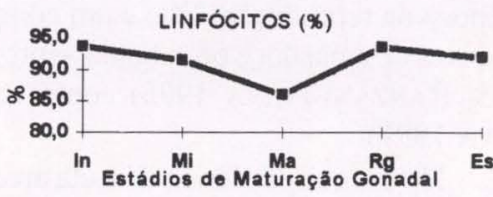

MONOCITOS (\%)

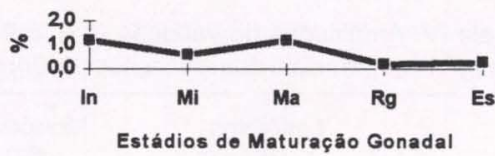

NEUTRÓFILOS (\%)
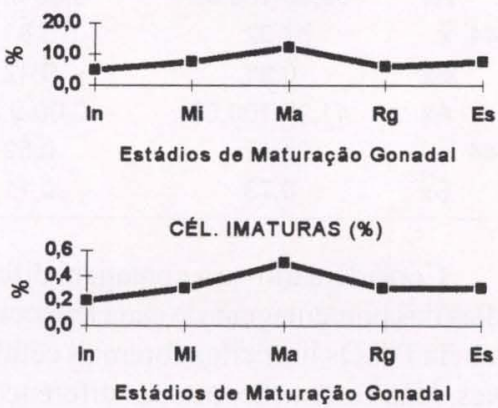

Fig. 3. Médias das porcentagens dos leucócitos em O. mykiss, diplóides (2n) e triplóides (3n), por estádio de maturação gonadal. (In) Indeterminado, (Mi) maturação inicial, (Ma) maturação avançada, (Md) maduro, $(\mathrm{Rg})$ regressão, (Es) estéril.

\section{CONCLUSÕES}

Para a constatação da triploidia, a medida do diâmetro dos eritrócitos é recomendada, tanto com extensões sangüíneas a fresco como com coradas por corantes hematológicos.

As diferenças hematológicas encontradas foram devidas à ploidia e aos estádios de maturação sexual. 
AGRADECIMENTOS. As autoras agradecem ao PqC Benedicto do Espírito-Santo de Campos, do Instituto de Zootecnia de São Paulo, pelas análises estatísticas e ao Biólogo Clóvis Guimarães Salinos pelo auxílio nas coletas e nas análises dos resultados.

\section{REFERÊNCIAS BIBLIOGRÁFICAS}

BECK, M.L. \& C.J. BIGGERS. 1983. Erythrocyte measurements of diploid and triploid Ctenophryngodon idella $x$ Hypophthalmichthys nobilis hibrids. Jour. Fish Biol. 22: 497-502.

Benfey, T.J. \& A.M. SuTTERLin. 1984a. Oxygen utilization by triploidy landlocked Atlantic salmon (Salmo salar L.). Aquaculture 42: 69-73

- 1984b. The haematology of triploid landlocked Atlantic salmon, Salmo salar L. Jour. Fish Biol. 24 (3): 333-338.

Benfey, T.J.; A.M. SutTerlin; R.J. \& ThOMPSON. 1984. Use of erythrocyte measurements to identify triploid salmonids. Can. Jour. Fish. Aquat. Sci. 41 (6): $980-984$.

BYE, V.J. \& R.F. LINCOLN. 1986. Comercial methods for the control of sexual maturation in rainbow trout (Salmo gairdneri R.). Aquaculture 57: 299-309.

CHERFAS, N.B. 1966. Natural triploiy in females of the unisexual form of goldfish (Carassius auratus gibelio Bloch). Soviet Genet. 2 (5): 9-13.

Chourrout, D. 1980. Thermal induction of diploid gynogenesis and triploidy in the eegs of the rainbow trout (Salmo gairdneri Richardson). Reprod. Nutr. Dévelop. 20 (3): 727-733.

CIMINO, M.C. 1973. Karyotypes and erythrocyte size of some diploid and triploid fishes of the genus Poeciliopsis. Jour. Fish. Res. Bd. Can. 30: 1736-1737.

COLLIER, H.B. 1944. The standardization of blood haemoglobin determinations. Can. Med. Ass. Jour. 50: 550-552.

Costa Neto, P.L. 1977. Estatística. São Paulo, Edgard Blüncher, 246p.

DONALDSON, E.M. \& G.A. HunTER. 1982. Sex control in fish with particular reference to salmonids. Can. Jour. Fish. Aquat. Sci 39: 99-110.

GoldenFARB, P.B.; F.P. Bowyer; E. Hall \& E. Brosius. 1971. Reproducibility in the hematology laboratory: The micro-hematocrit determinations. Amer. Jour. clin. Pathol. 56 (1): 35-39.

GRAHAM, M.S.; G.L. FLETCHER \& T.J. BENFEY. 1985. Effect of triploidy on blood oxygen content of Atlantic salmon. Aquaculture 50: 133-139.

HARDIG, J. \& L.B. Hoglund. 1984. Seasonal variation in blood components of reared Baltic salmon, Salmo salar L. Jour. Fish Biol. 24 (5): 565-579.

HARVEY, W.R. 1987. User's guide for LSMLMW: Mixed model-version. Ohio State University, 59p.

IHSSEN, P.E.; L.R. MCKAY; I. MCMILlan \& R.B. PHILLIPS. 1990. Ploidy manipulation and gynogenesis in fishes: citogenetic and fisheries applications. Trans. Amer. Fish. Soc. 119: 698-717.

LINCOLN, R.S \& A.P. SCOTT. 1984. Sexual maturation in triploid rainbow trout, Salmo gairdneri Richardson. Jour. Fish Biol. 25: 385-392.

MCCARTHY, D.H.; J.P. STEVENSON \& M.S. RoBERTS. 1973. Some blood parameters of the rainbow trout (Salmo gairdneri Richardson) I. The Kamloops variety. 
Jour. Fish Biol. 5: 1-8.

MEAdE, T.L. \& S.J. PERrone. 1980. Selective haematological parameters in steelhead trout, Salmo gairdneri Richardson. Jour. Fish Biol. 17 (1): 9-12.

PAIVA, M.J.T.R. 1991. Características sangüíneas da pirapitinga do sul, Brycon sp., sob condições experimentais de criação intensiva. Braz. Jour. Vet. Res. Anim. Scie. 28 (2): 141-153.

Paiva, P.; H.M. Godinho; C.S.R. Mainardes-Pinto; Y.A. Tabata \& R.G. LEITE. 1985. Comportamento reprodutivo de truta arco-íris, Salmo irideus Gibbons (Osteichithyes, Salmonidae), em cultivo intensivo. Bol. Inst. Pesca 12 (4):61-70.

PAlacios, L.; G. Viscor; J. PAlOMEQUE. 1987. Comparative study of two methods to determine erythrocyte dimensions in vertebrates. An. Fac. Vet. León 33: 53-60.

PICKERING, A.D. 1986. Changes in blood cell composition of the brown trout, Salmo trutta L., during the spawning season. Jour. Fish Biol. 29: 335-347.

Purdom, C. E. 1983. Genetic engineering by the manipulation of chromosomes. Aquaculture 33: 287-300.

RANZANI-PAIVA, M.J.T. 1995. Características hematológicas da tainha, Mugil platanus Günther, 1880 (Osteichthyes, Mugilidae) da região estuarino-lagunar

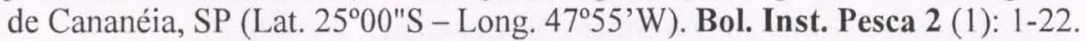

RanZANi-PAIVA, M.J.T. \& H.M. GodinHO. 1985. Estudos hematológicos em curimbatá, Prochilodus scrofa Steindachner, 1881 (Osteichthyes, Cypriniformes, Prochilodontidae). Série vermelha. Bol. Inst. Pesca 12 (2): 25-35.

Rosenfeld, G. 1947. Corante pancrômico para hematologia e citologia clínica. Nova combinação dos componentes do May-Grünwald e do Giemsa num só corante de emprego rápido. Mem. Inst. Butantan 20: 329-334

SeZAKI, K.; S. WATANABE \& K. Hashimoto. 1988. Haematological parameters and erythocyte enzyme activities associated with increase in ploidy status of the spinous loach, Cobitis biwae Jordan and Snyder. Jour. Fish Biol. 32 (1): 149-150.

SMALl, S.A \& T.J. BENFEY. 1987. Cell size in triploid salmon. Jour. Exp. Zool. 241: 339-342.

SWARUP, H. 1959. Effect of triploidy on the blood size, general organization and cellular structure in Gasterosteus aculeatus (L). Jour. Anat. 56: 143-155.

ThORGAARD, G.H. 1983. Chromosome set manipulation and sex control in fish, p.405-434. In: W.S. HoAR; D.J. RANDALl \& E.M. DONALdSON (Eds). Fish physiology. New York, Academic Press, vol. 9B.

UtTer, F.M.; O.W. Johnson; G.H. ThorgaArd \& P.S. Rabinovitch. 1983. Measurement and potencial aplications of induced triploidy in Pacific salmon. Aquaculture 35: 125-135.

VIRTANEN, E.; L. ForSMAN \& A. SUNDBY. 1990. Triploidy decreases the aerobic swimming capacity of rainbow trout (Salmo gairdneri). Comp. Biochem. Physiol. 96A (1): 117-121.

WINTROBE, M.M. 1934. Variations in the size and hemoglobin content of erythrocytes in the blood of various vertebrates. Folia Hematologica 51: 32-49.

Recebido em 29.VIII.1997; aceito em 01.XII.1998. 